\title{
WANITA DAN NERAKA \\ (Telaah Kritis Terhadap Hadis Banyaknya Wanita yang Menjadi Penghuni Neraka)
}

\author{
Syafira Sulistiani*
}

\begin{abstract}
Abstrak
Nabi saw. pernah bersabda bahwa mayoritas penghuni neraka adalah wanita, hadis ini terlihat seperti merendahkan wanita. Namun hadis ini disebut sebanyak 17 kali dalam kutub al-sittah dan kualitas hadis ini masuk dalam kategori shahih. Tetapi sebagai seorang muslim, kita tidak bisa menerima begitu saja. Diperlukan studi kritis terhadap hadis banyaknya wanita yang menjadi penghuni neraka. Studi kritis dilakukan dengan (1) Pendekatan tekstual yakni metode memahami makna dan maksud yang terkandung dalam hadis-hadis Nabi dengan cara bertumpu pada analisis teks hadis, (2) Pendekatan antar-tekstual yakni metode pemahaman hadis dengan memperhatikan hadis lain (tanawwu') dan/atau ayat-ayat Al-Qur'an yang terkait, dan (3) Pendekatan kontekstual yakni metode memahami hadis dengan melihat sisi-sisi konteks yang berhubungan dengan hadis. Dari studi kritis tersebut, menunjukkan bahwa maksud dari hadis bukan untuk merendahkan wanita, tetapi berlaku untuk pria maupun wanita yang tidak taat maka akan masuk ke neraka. Hadis ini juga menjadi peringatan bagi wanita (secara umumnya) untuk selalu melakukan perbuatan baik kepada siapapun, terutama suaminya dan selalu menjaga muru'ah atau kehormatan dirinya.
\end{abstract}

Kata Kunci : Pemahaman Hadis, Wanita, Neraka

\section{Pendahuluan}

Hadis ini sudah tidak asing didengar. Setiap membahas mengenai hadis ini, para wanita selalu merasa ngeri. Siapa yang ingin masuk neraka, tentu tidak ada. Setiap manusia pasti menginginkan untuk masuk surga. Namun, setelah mendengar hadis ini, bisa jadi timbul rasa kecewa dan sikap skeptis terhadap hadis Nabi. Hadis ini, bagi kaum feminis ${ }^{1}$ dianggap sebagai hadis misoginis², sebab terkesan memojokkan dan merendahkan perempuan. Padahal Nabi Muhammad sekalipun tidak pernah merendahkan perempuan. Bahkan sesungguhnya Nabi Muhammad-lah yang telah mengangkat derajat perempuan lebih mulia daripada laki-laki.

Seperti hadis tentang menghormati ibu, bahkan diulangi sebanyak tiga kali, kemudian baru ayah', Selain itu dapat juga dilihat dari bagaimana keadaan sebelum Islam datang, perempuan sangatlah tidak dianggap bahkan tidak mempunyai hak untuk hidup, bayi-bayi perempuan dikubur hidup-hidup. Kemudian Islam datang mengangkat derajat perempuan dan melepaskan perempuan dari belenggu keteraniayaan. Islam telah mengangkat martabat perempuan dengan memberikan hak-hak yang telah sekian lama terampas dari 
tangannya serta menempatkannya secara adil.

Untuk itu, sebagai muslim, kita tidak bisa serta merta menolak hadis tersebut lantaran ia dikategorikan sebagai hadis 'misoginis'. Sebab hadis merupakan sumber rujukan Islam kedua setelah AlQur'an. Agar tidak jadi salah tafsir, tentunya perlu tinjauan kritis dalam memahami hadis mengenai 'banyaknya wanita yang menjadi penghuni neraka' ini. Dalam tulisan ini, penulis akan memaparkan kajian menganai hadis mengenai banyaknya wanita yang menjadi peghuni neraka, dimulai dari kualitas sanad dan matannya. Kemudian dilanjutkan pada pemahaman terhadap hadis ini.

\section{A. Hadis Banyaknya Wanita yang}

\section{Menjadi Penghuni Neraka}

Berikut teks hadis banyaknya wanita yang menjadi penghuni neraka

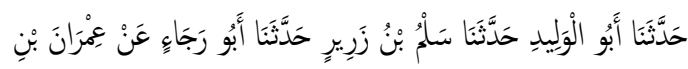

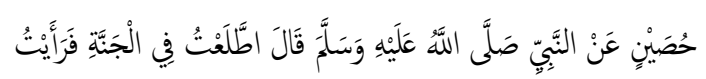

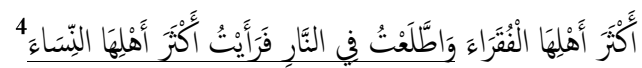
kami Abu al-Walid, telah menceritakan kepada kami Salm Ibn Zarir, telah menceritakan kepada kami Abu Raja' dari 'Imran Ibn Husain dari Rasulullah saw. Bersabda: saya memperhatikan surga, maka saya melihat mayoritas penduduknya adalah kaum fakir dan saya memperhatikan neraka, maka saya melihat mayoritas penduduknya adalah kaum wanita."

Penulis menelusuri hadis tersebut melalui dua jalur yakni berdasarkan kitab Mu'jam al-Mufahras li Alfaz al-Hadis alNabawi5, takhrij al-hadis dari hadis tersebut ditelusuri dengan kata kunci النّشَاء dengan

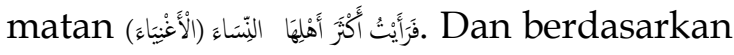
Lidwa Pusaka i-Software-Kitab 9 Imam Hadis, dengan menggunakan hadis riwayat Bukhari nomor 3002 sebagai hadis primer penulis mendapatkan hasil takhrij hadis mengenai banyaknya wanita yang menjadi penghuni neraka sebagai berikut ${ }^{6}$ :

Dari berbagai jalur tersebut, ada beberapa hadis yang meriwayatkan dengan lengkap asbab al-wurud hadis tersebut beserta penyebab wanita menjadi mayoritas penghuni neraka, diantaranya:

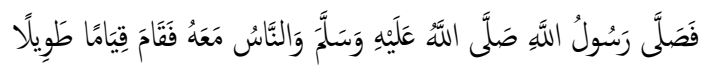

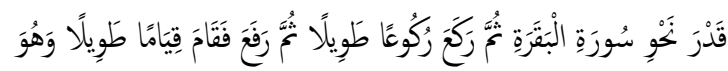

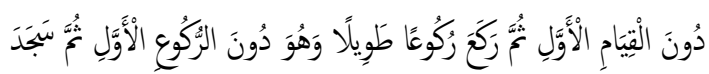

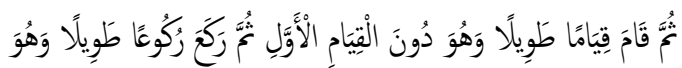

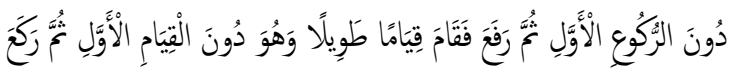

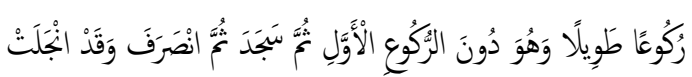

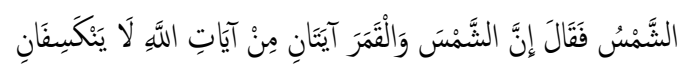

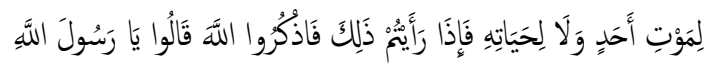

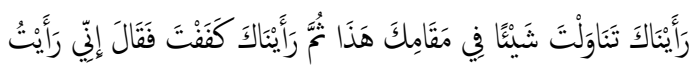




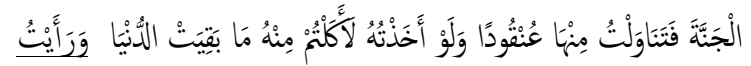

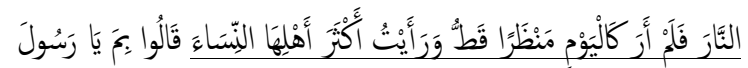

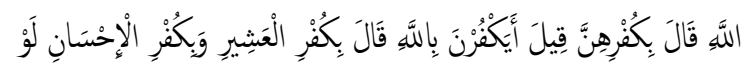

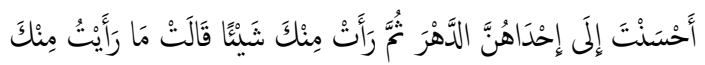

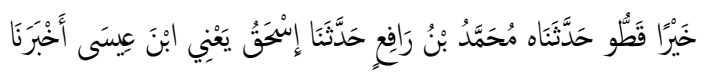

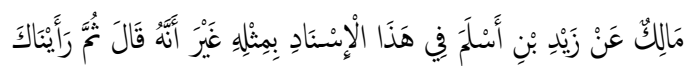
7 تَكْنَ

Dalam hadis tersebut dijelaskan bahwa saat itu Nabi sedang shalat gerhana. Pada saat shalat gerhana Nabi diperlihatkan oleh Allah neraka yang isinya kebanyakan adalah wanita. Setelah shalat para sahabat bertanya hal-ihwal yang menyebabkan wanita menjadi penghuni neraka yaitu kufur terhadap suami dan kebaikan-kebaikannya.

Berikut perawi yang meriwayatkan hadis tentang banyaknya wanita yang menjadi penghuni neraka melalui jalur Imam Bukhari nomor 3002.

\section{a. 'Imran Ibn Husain}

1) Nama lengkapnya: 'Imran Ibn Husain bin 'Ubaid Ibn Khalaf (w. 52 H). ${ }^{8}$

2) Kuniyah: Abu Najid.

3) Guru dan muridnya di bidang periwayatan hadis : Gurunya: Nabi saw., dan dari Mu'qil Ibn Yasar. Muridnya: al-Hasan al-Bashri, Abu Raja' al-'Utharidi, Abu al-Sawwar al'Adawi, Abu Qatadah al-'Adawi, dan lain-lain. ${ }^{9}$
4) Pernyataan para kritikus tentang dirinya: Ibn Hajar al-'Asqalaniy: Sahabat; Al-Dzahabi: Sahabat.

\section{b. Abu Raja' al-'Utharidi}

1) Nama lengkapnya: 'Imran Ibn Taymi (w. $107 \mathrm{H}$ ).

2) Kuniyah: Abu Raja'.

3) Guru dan murid di bidang periwayatan hadis: Gurunya: 'Abd Allah Ibn 'Abbas, dan 'Imran Ibn Hushain. Muridnya: Sa'id Ibn Abi 'Arubah Mihran, Salm Ibn Zarir, 'Imran Ibn Muslim, 'Auf, dan 'Amr Ibn 'Ubaid dan lain-lain. ${ }^{10}$

4) Pernyataan para kritikus tentang dirinya: (a) Yahya Ibn Ma'in: tsiqah, (b) Muhammad Ibn Sa'd: tsiqah, (c) Abu Zur'ah al-Razi, Ibn 'Abd al-Bar, serta Ibn Hibban menyebutkannya dalam alTsiqat. ${ }^{11}$

\section{c. Salm Ibn Zarir}

1) Nama lengkap: Salm Ibn Zarir al‘Utharidi

2) Kuniyah: Abu Bisyr al-Bashri.Ia merupakan perawi dari kalangan Tabi'in.

3) Guru dan murid di bidang periwayatan hadis: Gurunya: Buraid Ibn Abi Maryam al-Saluli, Abi Raja' al'Utharidi, dan Abi Ghalib. Muidnya: ‘Utsman Ibn 'Umar Ibn Faris, Abu alWalid Hisyam Ibn 'Abd al-Malik alThayalisi, dan lain-lain. ${ }^{12}$ 
4) Pernyataan para kritikus tentang dirinya: Abu Hatim: Tsiqah; Ibnu Hibban: tsiqah. ${ }^{13}$

\section{d. Abu al-Walid}

1) Nama lengkap: Hisyam Ibn 'Abd alMalik al-Bahili, lebih dikenal dengan sebutan Abu al-Walid al-Thayalisi al$\operatorname{Bashri14}^{14}$ (w. $\left.227 \mathrm{H}\right)^{15}$

2) Guru dan murid di bidang periwayatan hadis: Gurunya: Sufyan Ibn 'Uyaynah, Salm Ibn Zarir, Sulaiman Ibn Katsir al'Abdi, Sulaiman Ibn al-Mughirah. Muridnya : al-Bukhari, Abu Dawud, Ibrahim Ibn Khalid al-Yasykuri, dan lain-lain 16

3) Pernyataan para kritikus hadis tentang dirinya: Ahmad Ibn Hanbal : Mutqin; Ahmad Ibn Sinan, Abu Hatim : Amir alMuhadditsin; al-'Ajli: Tsiqah, Tsabat. ${ }^{17}$

\section{e. Imam Bukhari}

1) Nama lengkapnya: Abu 'Abd Allah Muhammad Ibn Isma'il Ibn Ibrahim Ibn al-Mughirah Ibn Badrdizbah alJu'fiy al-Bukhari (w. 256 H.) $)^{18}$

2) Guru dan murid di bidang periwayatan hadis: Gurunya : 'Ali ibn al-Madini, Ahmad ibn Hanbali, Abu al-Walid dan Ibn Rahwahih. Muridnya : Imam Muslim bin Al Hajjaj (pengarang kitab Shahih Muslim), al-Nasa'I, dan lainlain. ${ }^{19}$

3) Pernyataan para kritikus hadis tentang dirinya: Jumhur ulama menyebutnya dengan julukan Amir al-Mukminin fi alHadis (Pemimpin kaum mukmin dalam hal ilmu hadis). ${ }^{20}$

Jika disimpulkan, dari segi sanad, hadis ini memiliki sanad yang bersambung, meski ada beberapa parawi dalam penggunaan tahammul wa ada' hadis tidak mendengar secara langsung, namun, terlihat ada pertemuan antara setiap perawi, dibuktikan dengan adanya hubungan guru dan murid diantara perawi. Seluruh perawi bersifat adil dan dhabit, serta jika melihat syahid dan mutabi'-nya sangat sedikit kemungkinan adanya syadz dan 'illat pada matan. Sehingga penulis menyimpulkan bahwa hadis ini shahih.

\section{B. Pemahaman Terhadap Hadis Banyaknya Wanita yang Menjadi \\ Penghuni Neraka}

Untuk memahami hadis ini, penulis menawarkan tiga pendekatan pemahaman hadis, diantaranya (1) Pendekatan tekstual yakni metode memahami makna dan maksud yang terkandung dalam hadishadis Nabi dengan cara bertumpu pada analisis teks hadis, (2) Pendekatan antartekstual yakni metode pemahaman hadis dengan memperhatikan hadis lain (tanawwu') dan/atau ayat-ayat AlQur'an yang terkait, dan (3) Pendekatan kontekstual yakni metode memahami hadis 
dengan melihat sisi-sisi konteks yang berhubungan dengan hadis. ${ }^{21}$

Dengan melihat berbagai sisi, diharapkan mendapatkan pemahaman yang tepat terhadap hadis banyaknya wanita yang menjadi penghuni neraka ini.

\section{Pemahaman dengan Pendekatan Tekstual}

Kata teks bermakna "kata-kata asli dari pengarangnya" atau "sesuatu yang tertulis".22 Dari sini maka secara istilah pendekatan tekstual berkaitan dengan pemahaman hadis adalah memahami makna dan maksud yang terkandung dalam hadis-hadis Nabi dengan cara bertumpu pada analisis teks hadis.

Matan hadis ini diawali dengan lafadz اطَّلَُّ dengan mentasydidkan huruf tha' yang mempunyai arti أَشْرفتْ atau "saya mengawasi".23 Susunan lafadz أَّأَتُ bermakna "saya mengamati", sedang lafadz فَرَأَيْنَ bermakna "saya megetahui". ${ }^{24}$ Wanita ditulis dengan lafaz al-nisa' berarti wanita, namun lafaz al-nisa' biasanya dikontekskan dengan sifat feminism, artinya yang memiliki sifat itu tidak harus memiliki jenis kelamin perempuan. Berbeda dengan lafaz untsa yang lebih pada pemaknaan wanita (jenis kelamin). Jadi, secara tekstual, matan hadis ini bermakna "Aku (Rasulullah) mengamati isi neraka dan aku mengetahui bahwa kebanyakan dari penghuninya adalah kaum wanita.

\section{Pemahaman dengan Pendekatan Antar-Tekstual}

Pendekatan antar-tekstual yaitu suatu pendekatan dalam pemahaman hadis dengan memperhatikan hadis lain (tanawwu') dan/atau ayat-ayat AlQur'an yang terkait. ${ }^{25}$ Dalam Al-Qur'an, terdapat beberapa ayat yang menghubugkan antara manusia dan balasan yang akan didapatkan kelak. Apakah itu surge atau neraka. Namun sejauh yang penulis teliti, tidak ada ayat yang menyebutkan bahwa mayoritas penduduk neraka adalah wanita.

Dengan pendekatan Al-Qur'an, dipahami bahwa Allah akan memberi jaminan secara adil baik kepada laki-laki maupun perempuan yang beriman dan beramal shalih dengan surga. Begitu pula sebaliknya, jika ia kufur dan tidak beramal shalih maka balasannya adalah neraka. Jika banyak wanita masuk neraka, maka itulah yang pantas ia dapatkan, 'mungkin saja' memang banyak wanita yang tidak menaati Allah.

Sedang jika ditilik dengan pendekatan hadis, penulis mendapatkan beberapa hadis yang berkaitan dengan hadis banyaknya wanita yang menjadi penghuni neraka, khusunya mengenai 
penyebab wanita bisa menjadi penghuni neraka, diantaranya:

a. Karena Kufur 26 Terhadap Suami dan Kebaikan-Kebaikannya

Terkait dengan sikap kufur terhadap suami, Ibn Hajar dalam kitabnya, Fath alBari, mengutip penjelasan al-Qadli Abu Bakar Ibn al-'Arabi sebagai berikut:

"Hadis ini mengisyaratkan adanya jenis ke-kufur-an lain yang berbeda dari kufur kepada Allah swt., yakni, kufur kepada suami, dikhususkan dalam hadis ini dibanding jenis-jenis dosa lainnya disebabkan adanya rahasia yang tersembunyi. Hadis di atas menegaskan bahwa suami dari segi hak yang harus dipenuhi oleh seorang istri berada pada level kedua di bawah Allah swt. Kalau seorang istri mengabaikan hak seorang suami, padahal suaminya sudah memenuhi hak istri tersebut, berarti ini merupakan pertanda bahwa istri mengabaikan hak Allah. Oleh karena itu diungkapkan oleh Nabi saw.dengan pernyataan "kufur", meskipun kufur-nya tidak sampai keluar dari Islam. ${ }^{27 \prime}$

Ke-kufur-an sejenis ini dapat berupa seorang isteri yang mengingkari kebaikankebaikan suaminya selama sekian waktu yang panjang hanya dengan sikap suami yang tidak sesuai dengan kehendak isteri. Padahal yang harus dilakukan oleh seorang isteri ialah bersyukur terhadap apa yang diberikan suaminya, sebab Allah swt. tidak akan melihat isteri yang kufur terhadap suami.

Hadis di atas adalah peringatan keras bagi kaum wanita muslimah yang menginginkan keridlaan dan surga-Nya. Maka tidak sepatutnya bagi wanita yang mengharapkan akhirat namun mengkufur-i kebaikan dan nikmat yang diberikan suami atau meminta dan banyak mengadukan kekurangan suami.

b. Karena Kebiasaan Mengumpat/Menggunjing

Rasulullah saw. keluar waktu Ied Adha atau Ied Fitri dan melewati para wanita dan bersabda: "Wahai para wanita, keluarkanlah shadaqah karena saya diperlihatkan bahwa kebanyakan penghuni neraka adalah dari kalangan kalian. Mereka berkata, 'Kenapa wahai Rasulullah? Beliau bersabda: “Kalian sering mengumpat, dan mengingkari pasangan. $^{28}$

Bagian awal matan hadis itu menunjukkan konteks yang dimaksudkan di depan. Nabi menyatakan sabdanya itu di jalan ketika beliau menuju lapangan untuk melakukan salat Idul Fitri atau Idul Adha. Yang mana kedua salat sunat ini disyari'atkan setelah Hijrah. Ini berarti 
Nabi melakukan dialog itu di dalam satu jalan di Madinah.

Jalan-jalan di Madinah ketika itu seperti jalan-jalan di pemukiman yang lain, dulu dan sekarang, juga biasa digunakan baik oleh laki-laki maupun perempuan untuk 'kongkow-kongkow'. Kebiasaan ini diantaranya melatarbelakangi turunnya Surah al-Nur [24]: 30$31^{29}$ yang berisi perintah kepada kaum Mukminin untuk menundukkan pandangan mata. Kebiasaan ini nampaknya kuat berakar di kalangan penduduk Madinah. Nabi pernah bermaksud untuk melarang kebiasaan itu. Namun, banyak orang yang berkeberatan sehingga beliau membolehkan para sahabat tetap melakukannya dengan syarat mereka harus mau memenuhi hakhak jalan. ${ }^{30}$ Hak-hak itu diantaranya: (1) menundukkan pandangan mata; (2) menahan diri dari menyakiti pihak lain; (3) menjawab salam; (4) menganjurkan yang $m a^{\prime}$ ruf dan melarang yang munkar.

Berkaitan dengan ini ada kekosongan informasi tentang perempuan yang dijumpai Nabi di jalan itu, apakah mereka sedang 'kongkow-kongkow', lewat, atau sedang melakukan kegiatan yang lain. Mengingat kuatnya kebiasaan itu, nampaknya mereka saat itu sedang 'kongkow-kongkow'. Pertanyaannya kemudian adalah apa saja yang mereka bicarakan dalam 'kongkow-kongkow'. 31

Dalam hadis itu terdapat informasi mengenai apa yang mereka bicarakan yaitu kebiasaan sering "mengumpat". Dari kebiasaan yang dilakukan, mereka sering terbawa oleh situasi, sehingga mereka tidak bisa memenuhi hak-hak jalan yang disebutkan dalam hadis dari Abu Sa'id al-Khudri itu. Mereka bukannya menahan pandangan mata, tetapi malah mengumbarnya, bahkan mengombar mulut mereka untuk menggunjing dan menyoraki orang-orang yang lewat. 32

Kemungkinan perempuan yang dijumpai Nabi itu menggunjing orang yang lewat. Hal ini sudah barang tentu membuat Nabi gemas. Kegemasan itu bertambah ketika mengetahui hal itu mereka lakukan saat hari raya yang seharusnya diisi dengan kebaikan, tidak dengan kemungkaran. Nabi menasihati para wanita agar banyak bersedekah. Di antara keutamaan sedekah, antara lain, orang bersedekah berhak mendapat rahmat Allah ${ }^{33}$. Sedekah akan menjadi naungan di akhirat saat tidak ada naungan, kecuali naungan Allah. “Barang siapa yang memberikan penangguhan kepada orang yang mengalami kesulitan atau membayarkan hutangnya, maka 
Allah akan menempatkannya pada hari kiamat kelak berada di bawah naungan 'Arsy-Nya, pada hari dimana tidak ada naungan selain naungan-Nya" ${ }^{34}$

c. Tidak Bisa Mencium Bau Surga Karena Mengumbar Aurat

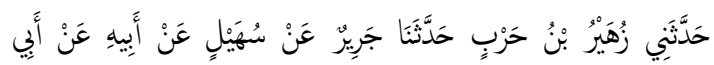

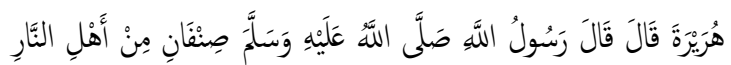

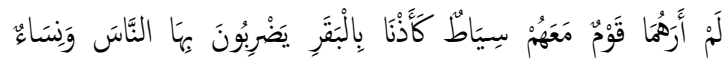

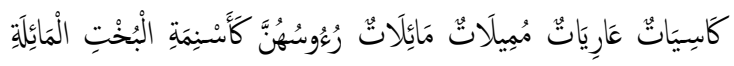

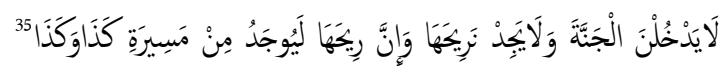

Artinya: "Telah menceritakan kepadaku

Zuhair Ibn Harb telah menceritakan kepada kami Jarir, dari Suhail dari ayahnya dari Abi Hurairah ia bersabda, Rasulullah saw. bersabda: Ada dua golongan dari penduduk neraka yang belum pernah aku lihat: Suatu kaum yang memiliki cambuk seperti ekor sapi untuk memukul manusia dan para wanita yang berpakaian tapi telanjang, berlenggaklenggok, kepala mereka seperti punuk unta yang miring. Wanita seperti itu tidak akan masuk surga dan tidak akan mencium baunya, walaupun baunya tercium selama perjalanan sekian dan sekian."

Dalam hadis, pada poin nomor dua dijelaskan mengenai sebab-sebab wanita tidak akan masuk surga. Yakni para wanita yang berpakaian tapi telanjang, berlenggak-lenggok, kepala mereka seperti punuk unta yang miring. Imam al-
Nawawi dalam Syarh-nya atas kitab Shahih Muslim berkata: "Hadis ini merupakan salah satu mukjizat Rasulullah saw. Sehingga apa yang telah beliau kabarkan kini telah terjadi. ${ }^{36}$

$$
\text { Adapun "berpakaian tapi }
$$
telanjang", maka ia memiliki beberapa sisi pengertian. Pertama, artinya adalah mengenakan nikmat-nikmat Allah namun telanjang dari bersyukur kepada-Nya. Kedua, mengenakan pakaian namun telanjang dari perbuatan baik dan memperhatikan akhirat serta menjaga ketaatan. Ketiga, yang menyingkap sebagian tubuhnya untuk memperlihatkan keindahannya, mereka itulah wanita yang berpakaian namun telanjang. Keempat, yang mengenakan pakaian tipis sehingga menampakkan bagian dalamnya, berpakaian namun telanjang dalam satu makna. ${ }^{37}$

Sedangkan "ma`ilaatun mumilatun", maka ada yang mengatakan: menyimpang dari ketaatan kepada Allah dan apa-apa yang seharusnya mereka perbuat, seperti menjaga kemaluan dan sebagainya."Mumilat" artinya mengajarkan perempuan-perempuan yang lain untuk berbuat seperti yang mereka lakukan. Ada yang mengatakan, "ma 'ilat" itu berlenggak-lenggok ketika berjalan, sambil menggoyang-goyangkan pundak. Ada yang mengatakan, "ma ilat" 
adalah yang menyisir rambutnya dengan gaya condong ke atas, yaitu model para pelacur yang telah mereka kenal. "Mumilat" yaitu yang menyisirkan rambut perempuan lain dengan gaya itu. Ada yang mengatakan, "ma ilat" maksudnya cenderung kepada laki-laki. "Mumilat" yaitu yang menggoda laki-laki dengan perhiasan yang mereka perlihatkan dan sebagainya. 38

Adapun "kepala-kepala mereka seperti punuk-punuk unta", maknanya adalah mereka membuat kepala mereka menjadi nampak besar dengan menggunakan kain kerudung atau selempang dan lainnya yang digulung di atas kepala sehingga mirip dengan punukpunuk unta.Ini adalah penafsiran yang masyhur. Al Maziri berkata: "dan mungkin juga maknanya adalah bahwa mereka itu sangat bernafsu untuk melihat laki-laki dan tidak menundukkan pandangan dan kepala mereka." 39

d. Wanita Masuk Neraka Karena Menyakiti Kucing

Rasulullah saw. setelah shalat gerhana bersabda:

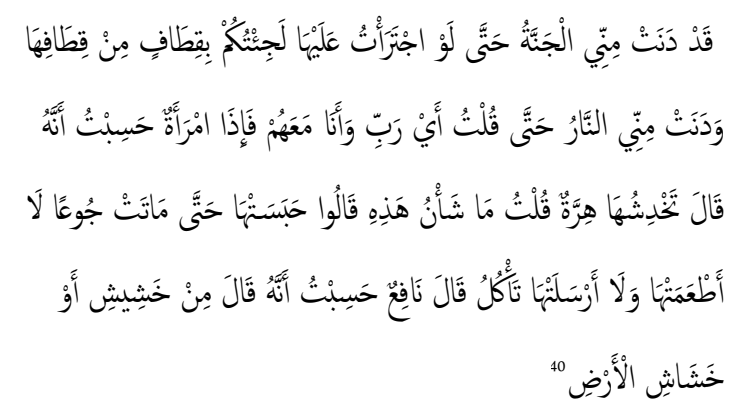

Artinya: "Telah didekatkan surga kepadaku hingga seandainya aku dibenarkan (berani) untuk mengambilnya tentu aku akan bawakan kepada kalian kurma dari kurmakurma didalamnya. Dan didekatkan juga neraka kepadaku hingga aku berkata, 'Wahai Rabb, aku bersama mereka.Tiba-tiba aku melihat seorang wanita'.Aku (Nafi') menduga beliau mengatakan, "Dicakar-cakar oleh seekor kucing.Aku bertanya, 'Apa yang menyebabkan demikian?Mereka menjawab, 'Wanita tersebut menahan kucing tersebut hingga mati karena kelaparan karena dia tidak memberinya makan atau membiarkan kucing tersebut pergi mencari makan.' Nafi' berkata, "Aku menduga beliau mengatakan, "Mencari makan dari serangga di permukaan tanah'."

Hadis ini menceritakan tentang seorang wanita Himriyyah, di riwayat lain disebutkan bahwa ia berasal dari Bani Isra'il. Ia mengurung seekor kucing, tetapi dia tidak memberinya makan dan minum hingga kucing itu mati karena kelaparan dan kehausan. Ini menunjukkan kerasnya tabiat wanita itu, betapa buruk akhlaknya, serta tiadanya belas kasih di hatinya. Dia sengaja menyakiti kucing.Jika di hatinya terdapat belas kasih, niscaya dia melepaskan kucing itu. Dan sepertinya dia mengurungnya sepanjang siang dan malam. ${ }^{41}$

Imam Nawawi berkata: "Hadis ini menunjukkan diharamkannya membunuh 
kucing dan diharamkan mengurungnya tanpa diberi makanan dan minuman. Adapun dimasukkannya dia ke dalam neraka adalah karena perbuatan itu. Zhahir hadis menunjukkan bahwa perempuan tersebut beragama Islam, meskipun demikian dia masuk neraka karena menyiksa seekor kucing. ${ }^{42}$

e. Wanita Mudah Masuk Surga

Sesungguhnya jalan menuju surga untuk wanita sangatlah luas. Hal ini dapat dilihat dari hadis riwayat Imam Ahmad berikut ini:

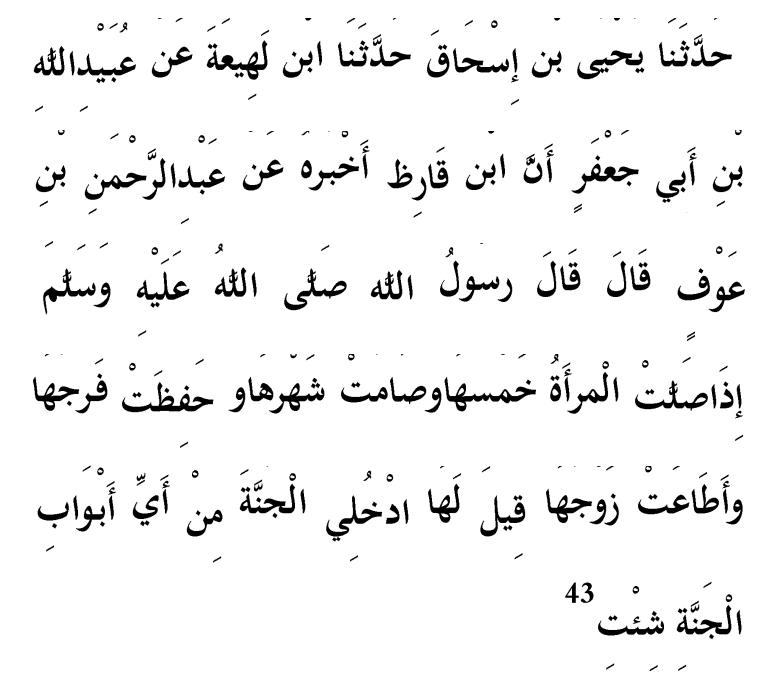

Artinya: "Telah menceritakan kepada kami Yahya ibn Ishaq telah menceritakan kepada kami Ibn Lahi'ah dari 'Ubaid Allah Ibn Abi Ja'far sesungguhnya Ibn Qaridz telah mengabarinya dari 'Abd al-Rahman ibn 'Auf berkata, Rasulullah saw. bersabda: "Apabila seorang wanita mendirikan shalat lima waktu, berpuasa sebulan (Ramadhan), menjaga kehormatan dan taat kepada suami, dia akan disuruh memasuki syurga melalui mana-mana pintu yang dia sukai."
Dengan melakukan empat hal tersebut (1) Shalat lima waktu (2) Berpuasa ramadhan (3) Menjaga kehormatan dan (4) Taat kepada suami, maka wanita berhak masuk surga dari pintu manapun.

\section{Pemahaman dengan Pendekatan Kontekstual}

Edi Safri memberikan pengertian terhadap pemahaman kontekstual atas hadis, menurutnya pemahaman kontekstual atas hadis atau kontekstualisasi hadis ialah memahami hadis-hadis Rasulullah dengan memperhatikan dan mengkaji keterkaitannya dengan peristiwa atau situasi yang melatarbelakangi munculnya atau dengan kata lain memperhatikan dan mengkaji konteksnya. ${ }^{44}$

Salamah Noorhidayati, dalam disertasinya mengatakan ada tiga versi mengenai maksud dari hadis banyaknya wanita yang menjadi penghuni neraka, diantaranya 45 :

- Yang dilihat Nabi adalah penghuni neraka sampai pada saat Nabi melihatnya, bukan seluruh manusia sampai hari akhir.

- Prediksi mayoritas manusia adalah perempuan, sebagaimana yang diriwayatkan oleh Imam Bukhari ${ }^{46}$. 
- Nabi melihat perbuatan sebagai bentuk kiasan yang bisa menjadikan seseorang menjadi penghuni neraka, sebagaimana perbuatan-perbuatan lain yang bisa menjadi sebab masuk neraka.

Hadis mengenai banyaknya wanita yang menjadi penghuni neraka ini disabdakan Nabi saat beliau bersama para sahabat sedang shalat gerhana matahari. Sedang dalam syarah Fath al-Bari dijelaskan bahwa hadis mengenai banyaknya wanita yang menjadi penghuni neraka ini merupakan penglihatan Nabi saat melakukan Isra' dan Mi'raj. Pada waktu itu Nabi singgah ke surga dan neraka, dan melihat keadaan manusia yang berada disana. Ada pula ulama yang berpendapat itu bukanlah pengalaman Nabi saat Isra' dan Mi'raj, melainkan mimpi Nabi Muhammad. ${ }^{47}$

Dan juga, seperti yang telah dilampirkan pada subbab sebelumnya, hadis ini disabdakan Nabi setelah keluar dari shalat 'Ied al-Adha atau al-Fithr.48 Saat hari raya yang seharusnya diisi dengan kebaikan, namun, oleh wanita-wanita Madinah diisi dengan kemungkarankemungkaran yang telah dijelaskan diatas. Sehingga Nabi yang berperangai halus menasehati mereka dengan mengatakan bahwa penghuni neraka terbanyak adalah golongan wanita. 49
Hadis ini disampaikan Rasul sekitar 14 abad yang lalu, kemudian bagaimana jika dikontekskan untuk zaman sekarang. Secara sederhana dapat kita katakan bahwa hadis ini merupakan sebuah 'pesan' bagi wanita untuk selalu menjaga dirinya dari perbuatan-perbuatan yang dapat mengantarkan dirinya masuk ke dalam neraka.

Hadis mengenai banyaknya penghuni neraka adalah wanita merupakan sebatas peringatan dini saja untuk kaum wanita agar lebih berhatihati. Sebab, Nabi saw.juga menyatakan bahwa kebanyakan penghuni surga adalah orang-orang miskin. Tentu ini tidak berarti bahwa Nabi saw.merendahkan orang-orang kaya yang banyak ke neraka, melainkan sebatas peringatan dini kepada orang kaya agar mereka tidak terlena dengan kekayaannya.

Hadis di atas menyebutkan sifat yang menjadi penyebab masuk neraka. Sebagaimana halnya ayat dan hadis lainnya yang sering menyinggung tentang sifat dan sikap yang akan memasukkan ke neraka, berarti yang harus diperhatikan sifatnya itu sendiri, bukan jenis kelaminnya. Ini diperkuat oleh riwayat lain yang menitikberatkan pada sifat 
wanita yang menjadi penyebab masuk nerakanya, bukan jenis kelaminnya.

Dengan kata lain, maksud hadis perempuan banyak menjadi penghuni neraka itu adalah dari kalangan perempuan kebanyakannya yang kufur pada kebaikan suaminya. Jadi titik tekannya bukan pada perempuannya, tetapi pada sifat kufur terhadap kebaikan suaminya.

Dalam hal ini, maka berlaku juga kebalikannya. Seorang lelaki, jika ia memang mempunyai sifat yang akan menjadi penyebab ia masuk neraka, maka ia akan masuk neraka. Walau disebut lelakinya, bukan berarti merendahkan jenis kelaminnya, karena hadis hanya menyatakan sifatnya.

\section{Kesimpulan}

Setelah melakukan penelitian mengenai hadis banyaknya wanita yang menjadi penghuni neraka, penulis menyimpulkan bahwa hadis ini berkualitas shahih. Sehingga dapat dijadikan sebagai hujjah. Namun, dalam pemahamannya, perlu diperhatikan lagi bahwa hadis ini tidak dapat dipahami secara tekstual. Perlu pendekatan lain dalam melakukan interpretasi.

Misalnya dengan pendekatan antartekstual, yakni mengaitkan hadis banyaknya wanita yang menjadi penghuni neraka ini dengan Al-Qur'an dan hadis. Dari pendekatan Al-Qur'an didapatkan bahwa Allah berlaku adil terhadap lakilaki dan perempuan, terutama dalam hal pembalasan hari akhir, apakah itu surge ataukah neraka. Dalam beberapa ayat Allah menegaskan bahwa Dia telah menyiapkan surga bagi siapapun, tanpa membedakan jenis kelamin.

Sedang dari pendekatan hadis didapatkan hadis-hadis lain yang berhubungan. Misalnya tentang penyebab wanita bisa masuk neraka (1) kufur terhadap suami (2) mengumpat (3) tidak menjaga aurat dan (4) menyakiti binatang. Namun di sisi lain, wanita sangat mudah masuk surge. Asalkan melakukan empat syarat, yakni (1) shalat 5 waktu (2) puasa ramadhan (3) menjaga kehormatan (4) taat kepada suami.

Dari pendekatan kontekstual, didapati bahwa yang dimaksud hadis ini bukanlah merendahkan perempuan, namun sifat yang dilakukan oleh laki-laki atau perempuan manapun, yang tidak sesuai dengan ajaran agama, maka masuk neraka. Penulis berpendapat bahwa hadis ini merupakan peringatan bagi wanita (khususnya) untuk selalu berbuat baik terhadap siapa saja dan menjaga kehormatan. 


\section{Referensi}

1Feminisme (tokohnya disebut Feminis) adalah sebuah gerakan perempuan yang menuntut emansipasi atau kesamaan dan keadilan hak dengan pria.Feminisme berasal dari bahasa Latin, "femina" atau perempuan.Istilah ini mulai digunakan pada tahun 1890-an, mengacu pada teori kesetaraan laki-laki dan perempuan serta pergerakan untuk memperoleh hak-hak perempuan.Sekarang ini kepustakaan internasional mendefinisikannya sebagai pembedaan terhadap hak hak perempuan yang didasarkan pada kesetaraan perempuan dan laki laki. Lihat, http://id.wikipedia.org/wiki/Feminisme, diakses pada 27 Desember 2014 pukul 13.00

2Berasal dari bahasa Inggris, "misogyny" yang berarti kebencian terhadap wanita.Lihat, Jhon Echols dan Hassan Sadily, Kamus Bahasa InggrisIndonesia, (Jakarta: Gramedia, 1986), h. 382. Jadi, hadis misoginis yaitu hadis yang isinya memojokkan dan merendahkan derajat wanita.

${ }^{3} \mathrm{Abu}$ Abd. Allah Muhammad bin Ismail AlBukhari, (selanjutnya ditulis al-Bukhari)Al-Jami' alSahih (Sahih Bukhari) Kitab al-Adab Bab Man Ahaqqu al-Nas bi Husni al-Shahabah, Juz 7 Jilid 4,h. 69.

${ }^{4}$ Al-Bukhari, Sahih Bukhari ,Kitab Bad'u alKhalq Bab ma Ja'a min Shifati al-Jannah Juz 4 Jilid 2, h. 85 .

${ }^{5}$ Arnold John Wensinck, Mu'jam al-Mufahras li Alfaz al-Hadis al-Nabawi Jilid 6, (Leiden: E. J. Brill, 1943) h. 439

6Penomoran hadisnya penulis sesuaikan dengan yang ada pada Lidwa Pustaka i-Software

7Muslim ibn al-Hajjaj Abu al-Husain alQusyairi, Sahih Muslim, Kitab Kusuf Bab Ma ‘Uridla 'Ala Nabi, CD ROM Lidwa Pusaka i-Software no. 1512

${ }^{8}$ Lihat, al-Hafiz Jamal al-Din Abi al-Hajjaj Yusuf al-Mazzi (selanjutnya ditulis al-Mazzi), Tahzib al-Kamal fi Asma'I al-Rijal, (Beirut: Dar al-Fikr, t.tth) Juz 14, h. 381-382

9Lihat, al-Mazzi, Tahzib al-Kamal,Juz 14, h. 381 dan Imam al-Hafiz Abi Muhammad Abd. alRahman Ibn Abi Hatim (selanjutnya ditulis Abi Hatim), al-Jarh wa al-Ta'dil, (Beirut: Dar al-Kutub al'Ilmiyyah, 1971) Juz 6, h. 378.

10Al-Mazzi, Tahzib al-Kamal, Juz 21, h. 224.

11Ibid, h. 224
12Lihat, al-Mazzi, Tahzib al-Kamal, Juz 7, h. 399-400 dan Abi Hatim, al-Jarh wa al-Ta'dil, Juz 4, h. 245.

${ }^{13} \mathrm{Ibid}$, dan lihat pula al-'Asqalani, Tahdzib alTahdzib, Juz 4 (Beirut: Dar al-Fikr, t.th), h. 115.

14Lihat, al-Mazzi, Tahzib al-Kamal, Juz 19, h.

262.

${ }^{15}$ Abi Hatim, al-Jarh wa al-Ta'dil, Juz 9, h. 83

${ }^{16}$ Lihat, al-Mazzi, Tahzib al-Kamal, h. 262-263

dan Abi Hatim, al-Jarh wa al-Ta'dil, h. 83.

17Lihat, al-Mazzi, Tahzib al-Kamal, h. 264-265,

dan Abi Hatim, al-Jarh wa al-Ta'dil, h. 83.

${ }^{18}$ Abdul Majid Khon, Ulumul Hadis, (Jakarta:

Amzah, 2010) h. 259

${ }^{19} \mathrm{Ibid}, \mathrm{h} .259$.

20Ibid, h. 259

${ }^{21}$ Arifuddin Ahmad, Metode Tematik dalam Pengkajian Hadis (Sebuah Konstruksi Epistemologis), Makalah, UIN Alauddin Makasar, h. 13-14

22W.J.S. Poerwadarminta, Kamus Umum Bahasa Indonesia, (Jakarta:Balai Pustaka, 1985) h. 1035

${ }^{23 I b n u}$ Hajar Al-'Asqalani (selanjutnya ditulis al-'Asqalani), Fath al-Bari bi Syarh Shahih Bukari, Kitab al-Riqaq Bab Shifatu al-Jannah wa alNar Juz 11, (Beirut: Dar el-Hadith, 1998) h. 470

24Ibnu Abd al-Rahim Al-Mubarakfuri, Tuhfat al-Ahwadzi bi Syarh Jami' Tirmidzi no. 2527, CD Mausu'ah al-Hadis Syarif al-Kutub al-Tis'ah.

${ }^{25}$ Yusuf al-Qardhawi, Kajian Kritis Pemahaman Hadis, (Jakarta :Islamuna Press, 1991) h. 133

${ }^{26}$ Kufur dalam Kamus Besar Bahasa Indonesia berarti mengingkari dan tidak percaya kepada Allah dan Rasul-Nya. Tim Penyusun Kamus, Kamus Besar Bahasa Indonesia, (Jakarta: Balai Pustaka, 1989) h. 608. Sedang menurut Kamus Ilmu Alqur'an, yang dimaksud dengan kufur adalah mengingkari Allah dan segala ajaran-Nya yang dibawa oleh para Nabi dan Rasul-Nya. Sikap kufur inibermacam-macam, antara lain: kufur ni'mah, kufur 'amal, kufur 'inad, kufur iblis, dan lain sebagainya. Ahsin W. al-Hafidz, Kamus Ilmu Alqur'an,(Jakarta: Amzah, 2001) h. 160

27Lihat, al-'Asqalani, Fathul-Bari Kitab alIman Bab Kufran al-'Asyir, Juz 1 h. 104

${ }^{28}$ Al-Bukhari, Sahih Bukhari, Kitab al-Haidl Bab Tark al-Haidl al-Shaum, Juz 1 Jilid 1, h. 78

${ }^{29}$ Berbunyi: "Katakanlah kepada orang lakilaki yang beriman: "Hendaklah mereka menahan pandangannya, dan memelihara kemaluannya; 
yang demikian itu adalah lebih suci bagi mereka, sesungguhnya Allah Maha Mengetahui apa yang mereka perbuat. Katakanlah kepada wanita yang beriman: "Hendaklah mereka menahan pandangannya, dan memelihara kemaluannya, dan janganlah mereka menampakkan perhiasannya, kecuali yang (biasa) nampak daripadanya. Dan hendaklah mereka menutupkan kain kudung ke dadanya, dan janganlah menampakkan perhiasannya,..."

${ }^{30}$ Hamim Ilyas, dkk, Perempuan Tertindas?

(Kajian Hadis-Hadis Misoginis), (Yogyakarta: UIN Sunan Kalijaga, 2003) h. 64

31Ibid, h. 64

32Ibid,h. 64

33Lihat, QS al-A'raf [7]: 56 yang artinya: “Dan janganlah kamu membuat kerusakan di muka bumi, sesudah (Allah) memperbaikinya dan berdoalah kepada-Nya dengan rasa takut (tidak akan diterima) dan harapan (akan dikabulkan). Sesungguhnya rahmat Allah amat dekat kepada orang-orang yang berbuat baik."

${ }^{34}$ M. Khalilurrahman al-Mahfani, Wanita Idaman Surga, (Jakarta: Wahyu Media, 2013), h. 71

35Muslim, Sahih Muslim, Kitab al-Libas wa al-

Zinah Bab al-Nisa' al-Kasiyat al-'Ariyat al-Ma'ilat al-Mumilat, Juz 2, h. 254

36Al-Nawawi, Al-Minhāj fi Syarh Shahih Muslim bin al-Hajjäj,no. 3971,CD Hadis Syarif Kutub at-Tis'ah.

37Al-Nawawi, Al-Minhāj fi Syarh Shahìh Muslim bin al-Hajjāj,no. 3971,CD Hadis Syarif Kutub at-Tis'ah.

38Ibid

${ }^{39}$ Ibid

${ }^{40}$ Al-Bukhari, Shahih Bukhari, Kitab al-Adzan Bab Ma Yaqulu Ba'da al-Takbir, Juz 2, h. 68

41Al-'Asqalani, Fath al-Bari, Kitab Bad'u Khalq Bab Khams min al-Dawab no. 3071 CD Rom Mausu'ah

42Imam Al-Nawawi, Al Minhaj Syarh Shahih Muslim bin Hajjaj Juz 7 (Mesir: Dar el-Hadith. T.th) h. 347

${ }^{43}$ Ahmad bin Hanbal, Musnad Ahmad, no. 1573 Kitab Musnad al-'Asyrah al-Mubasysyirin alJannah Bab Hadis 'Abd. al-Rahman Ibn 'Auf alZuhri r.a., CD Mausu'ah al-Hadis Syarif al-Kutub al-Tis'ah.

${ }^{44}$ Liliek Channa AW, Memahami Makna Hadis Secara Tekstual dan Kontekstual, Jurnal Ulumuna Vol. 15 No. 2 Desember 2011 h. 390, mengutip dari Edi
Safri, Al Imam Asy-Syafi'i: Metode Penyelesaian HadisHadis Mukhtalif, Tesis (Fakultas Pascasarjana IAIN Syahid Jakarta, 1990).

45Salamah Noorhidayati, Menalar Pandangan

Hadis-Hadis Tentang Perempuan, Disertasi (Yogyakarta: Pascasarjana UIN Sunan Kalijaga, 2013) h. 148-149

${ }^{46}$ Al-Bukhari, Sahih Bukhari, Kitab al-`Ilm Bab Raf'u al-'Ilm wa Zuhur al-Jahl, Juz 1 h. 27

${ }^{47}$ Al-'Asqalani, Fathul-Bari Kitab al-Iman

Bab Kufran al-' Asyir, h. 104-105

48 Burhan al-Din Ibn Hamzah al-Dimasyqi, Al-Bayan wa al-Ta'rif fi Asbab al-Wurud al-Hadis, Juz 2, CD ROM Maktabah al-Syamilah, h. 306.

${ }^{49}$ Hamim Ilyas, dkk, Perempuan Tertindas?

(Kajian Hadis-Hadis Misoginis) h. 65 